\title{
Controle remoto nas mãos do leitor de jornais impressos
}

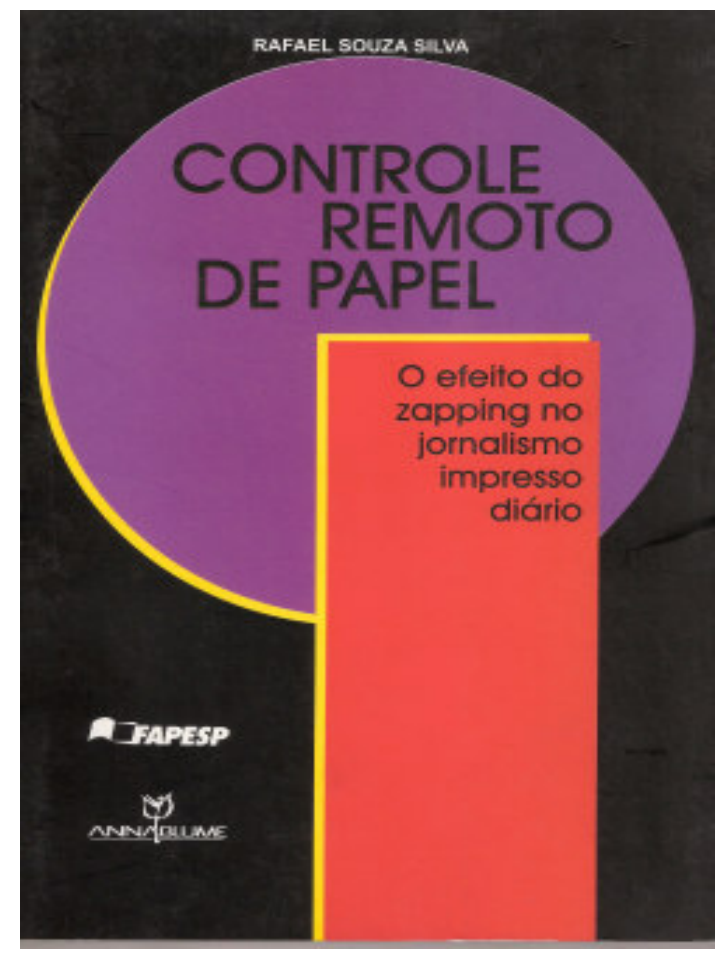

SILVA, Rafael Souza. Controle remoto de papel. O efeito zapping no jornalismo impresso diário. São Paulo: Annablume/ Fapesp, 2007.

\section{Ana Elisa Ribeiro}

Professora do Centro Federal de Educação Tecnológica de Minas Gerais/MG/BR anadigital@gmail.com
"Zapear" não é palavra que esteja no dicionário, ao menos não no Aurélio século XXI. Já a palavra zapping aparece como um substantivo masculino originado do inglês, com sentido de "seqüência de mudanças rápidas de um canal para outro, por meio de controle remoto, e que ger. é feita para evitar os intervalos comerciais". O "geralmente" é importante para modalizar a afirmação. De fato, muitas pessoas "zapeiam" no meio da programação, sem o menor pudor, apenas para saber o que há em outras transmissões. E na profusão de canais que um serviço a cabo, por exemplo, pode oferecer, "zapear" pode ser quase infinito. Quanto mais oferta de "informação", mais frenética pode ser essa "seqüência de mudanças rápidas", em que não se assiste a nada e talvez se tenha a vaga percepção do que vai aqui e ali. Não apenas a variedade de canais e os intervalos propiciam o zapping, mas também a existência do controle remoto, que facilita, com botões, a mudança dos programas. Uma tecnologia, portanto, complementa a outra e transforma tudo em uma nova prática (nem tão nova assim há algumas décadas). As emissoras tentam se esquivar como podem do leitor zapeador, sincronizando intervalos e tornando concorrentes programas parecidos, mas nem isso pode deter a gana "pisca-pisca" do telespectador que procura algo de seu interesse.

A associação que Rafael Souza Silva faz entre "zape$a^{\prime \prime}$ e ler jornais é, de fato, muito interessante. Na obra Controle remoto de papel. O efeito do zapping no jornalismo impresso diário provoca curiosidade desde a primeira passada de olhos pelo subtítulo. "Zapear" no impresso? Realmente, não se trata de uma comparação entre televisão e mídias digitais, por exemplo, em que talvez se pudesse falar em "zapping". Trata-se de considerar aquela leitura inicial dos jornais, uma espécie de "varredura" a que alguns chamam de "escaneamento" (o scannable, de Morkes e Nielsen), como uma forma de "zapear". E mais do que isso: tratar a tendência à "cadernização" dos jornais como uma forma de segmentar, "blocar", diversificar, categorizar, permitindo que o leitor transite com mais fluência apenas pelo que ele gosta, evitando "intervalos".

Rafael Souza Silva é autor do manual Diagramação Planejamento visual gráfico na comunicação impressa (Summus, 1985), em que trata de aspectos bastante técnicos do design de páginas de jornais. Em Controle remoto de papel ainda há resquícios, como não poderia deixar de ser, do designer de periódicos. Em vários momentos, o autor aborda o diagrama das páginas de jornais para mostrar como os impressos são lidos, como são desenhados e de que forma o zapping é possível nessas páginas. 
Em 170 páginas, a obra desenvolve a comparação de maneira bastante atraente, em uma linguagem acadêmica que não chega a impedir a leitura, por exemplo, de um curioso que não seja da área do jornalismo ou do design. Controle remoto de papel é resultado da edição da tese de doutoramento do autor, na PUC-SP, e traz, além do Prefácio, da Apresentação, da Conclusão e das referências bibliográficas, cinco capítulos que seguem o roteiro dos trabalhos acadêmicos. Na Introdução, o autor expõe seus modelos teóricos, mencionando mais fortemente a Semiótica da Cultura (especialmente em Ivan Bystrina). No capítulo I, Rafael Souza Silva faz um sobrevôo pela história das corporações jornalísticas, especialmente no Brasil. Começa a se desenhar aqui a idéia que permeia a obra: "Tudo no jornal é afetado por novas formas de edição que visam valorizar o conteúdo e o leitor ao mesmo tempo" (p. 23). Em tempos de "design de interação" e de "usabilidade", é sempre bom lembrar que o design gráfico também já se orientava pela legibilidade e pelas práticas do leitor (atual "usuário"), ao menos em escolas funcionalistas. Neste primeiro capítulo, Souza Silva inicia sua argumentação em torno da idéia de que a segmentação dos jornais foi uma tendência mais ou menos recente dos jornais, com origem "no comportamento editorial das revistas e, principalmente, na publicação em fascículos de assuntos específicos dos mais variados conteúdos" (p. 26). Ainda nesta parte, mostra-se o pioneirismo do Jornal do Brasil ao iniciar a "cadernização" e a "colorização" (note-se que na mesma época em que a tevê se popularizava).

O capítulo II aborda a importância do projeto voltado para a "sedução visual", incluindo-se aí uma diagramação atraente e a cor. O capítulo III dá seqüência a isso, abordando o "fator geométrico" e aprofundando explicações sobre direção de leitura e exemplos de espelhos de diagramas de páginas jornalísticas.

No capítulo IV, Rafael Souza Silva analisa, em particular, a Folha de S.Paulo e seu processo de "cadernização". Interessantíssimas são as páginas (em fac-símile) do jornal, na década de 1990, as alterações programadas ao longo do tempo e as explicações sobre mudanças de projeto gráfico publicadas à época. Verdadeiros documentos sobre mudanças gráficas importantes e suas motivações.

No quinto capítulo, o autor de Controle remoto de papel passa a tratar do "zapping", agora com o intuito de mostrar a história da tecnologia que permitiu o efeito e da adoção da prática de "zapear" pelos telespectadores, promovidos a "seletores" de programas. A comparação entre os "zapeares" em papel e na tevê surge mais claramente quando Souza Silva afirma:

O fenômeno do zapping não é um hábito recente como o controle remoto e como a televisão. Ele é oriundo da mais remota antiguidade, portanto, pode ser considerado como uma abstração. Contemporaneamente, ele já acontecia nas vanguardas artísti- cas no início do século XX, notadamente pelo pensamento futurista italiano, manifestava-se através da produção cultural, por meio da intimidade do leitor com o livro, jornal, revista, ao selecionar aquilo que mais the interessasse. (p. 138)

Apesar do texto nem sempre muito claro, é possível divisar aí o pressuposto um tanto sociológico de que o leitor sempre, a qualquer tempo, muito antes das "novas tecnologias de informação e comunicação", às voltas com a seleção. Dominique Wolton certamente se alinharia ao autor de Controle remoto de papel, ao menos neste ponto.

$\mathrm{Na}$ Conclusão do trabalho, à maneira das teses, Rafael Souza Silva "amarra" a leitura de jornais ao "zapping" e à mudança de projetos gráficos (especialmente na Folha de S.Paulo e no Jornal do Brasil) em direção à segmentação e às práticas do leitor.

Controle remoto de papel é original em relação aos estudos da comunicação que tratam de jornais. A mistura fina entre design, história dos projetos gráficos dos jornais, práticas telespectadoras e "design centrado no leitor" ajuda a compreender o que vem acontecendo aos veículos impressos sob um olhar diacrônico, mas, ao mesmo tempo, sob os impulsos da "concorrência" (às vezes discreta) com outras mídias. Tratar o "zapping" como um comportamento de leitura do impresso é, no mínimo, curioso. É mesmo necessário explicar a associação, para que ela não soe apenas uma aproximação meio "forçada" entre mídias mais tradicionais e mídias eletrônicas. O texto de Rafael Souza Silva ressente-se, também, de um excesso bastante incômodo de citações muito grandes de outros autores, num efeito de interrupção do texto que leva até mesmo ao abafamento da voz do pesquisador. A despeito disso e com boa vontade, o leitor do livro tira bom proveito da história da "cadernização" dos jornais no Brasil, para dizer o mínimo. É bastante provável que esta seja, ainda, uma das melhores oportunidades existentes para se discutir (tomara que com menos citações) as mudanças por que passa o jornalismo impresso na atualidade aAMECOS 